\title{
Using FRAM beyond safety: A case study to explore how sociotechnical systems can flourish or stall
}

\author{
Dominic Furniss $^{1 *}$, Paul Curzon ${ }^{2}, \&$ Ann Blandford ${ }^{1}$
}

${ }^{1}$ UCL Interaction Centre and UCL Institute of Digital Health, University College London, London, $U K$

${ }^{2}$ Queen Mary University of London, London, UK

* Corresponding author: Dominic Furniss d.furniss@ucl.ac.uk : UCL Interaction Centre, 2nd Floor, 66-72 Gower Street, University College London, Gower Street, London. WC1E 6BT. Tel. +44 (0)20 31087062

Co-authors

Paul Curzon p.curzon@qmul.ac.uk : School of Electronic Engineering and Computer Science, Queen Mary University of London, Mile End, London, E1 4NS.

Ann Blandford a.blandford@ucl.ac.uk : UCL Interaction Centre, 2nd Floor, 66-72 Gower Street, University College London, Gower Street, London. WC1E 6BT.

Authors' mini bios:

Dominic Furniss (d.furniss@ucl.ac.uk) is a Human Factors researcher with an interest in HCI and understanding sociotechnical systems; he is a senior research associate in the UCL Interaction Centre (UCLIC) of University College London (UCL).

Paul Curzon (p.curzon@qmul.ac.uk, http://www.eecs.qmul.ac.uk/ pc/) is a computer scientist with an interest in interaction design and the evaluation of human-computer systems; he is a Professor of Computer Science in the School of Electronic Engineering and Computer Science of Queen Mary University of London.

Ann Blandford (a.blandford@ucl.ac.uk, http://www.ucl.ac.uk/uclic/people/a_blandford) is a Human Factors expert with an interest in Digital Health and the situated use of technology; she is Professor of Human-Computer Interaction in the Department of Computer Science at UCL and Director of UCL Institute of Digital Health. 
Funding statement:

This work was supported by the UK Engineering and Physical Sciences Research Council under Grant [GR/S67494/01], [GR/S67500/01] and [EP/G059063/1].

Acknowledgements:

We would like to thank all the practitioners who gave their time to participate in this study. This article is based on the Ph.D. thesis of the first author.

Relevance to human factors/ergonomics theory:

This paper explores a new use of FRAM (Functional Resonance Analysis Method). Whereas previous uses have focused on accident analysis and risk assessment, we use FRAM to explore successful outcomes and gains in effectiveness. We show how FRAM can be used to investigate how complex sociotechnical systems flourish or stall. 
Using FRAM beyond safety: A case study to explore how sociotechnical systems can flourish or stall

FRAM (Functional Resonance Analysis Method) is a relatively new method that has been proposed to explore how functional variability can escalate into unexpected, and often unwanted, events. It has been used for accident analyses and risk assessments in safety. We apply (and slightly modify) FRAM, to analyse how functions are configured to create systems that excel. Our case study focuses on how functions in human factors project work positively resonate to improve the delivery of value. From interviews with 22 practitioners we derived 29 functions and 6 subsystems showing how functions are coupled. Practitioners validated this model through respondent validation. Our case study evaluates the applicability and usability of FRAM. It shows how we adapted the method to make it more usable. It shows that FRAM can be used to examine positive and negative resonance in systems, to investigate how complex sociotechnical systems can flourish or stall.

Keywords: FRAM; resilience engineering; human factors methods, performance; quality management

\section{Introduction}

FRAM (Functional Resonance Analysis Method) is a relatively new method that has been proposed to explore the functional coupling and performance variability in systems (Hollnagel 2004, 2012a). Despite claims that it can be used to analyse systems that result in positive outcomes, it has almost exclusively been used for safety, e.g. accident analyses and risk assessments. The aim of this paper is to evaluate the applicability and usability of FRAM.

Current applications of FRAM focus on monitoring and dampening functional resonance that amplifies uncontrolled performance variability to cause unexpected and unwanted outcomes. We change focus to positive resonance that amplifies the 
effectiveness of processes and the potential for successful outcomes. Our case study applies (and slightly modifies) FRAM to investigate how usability and human factors professionals manage variability to deliver value from project work. It shows how FRAM can be used for quality management purposes beyond the concerns of safety. We show that FRAM has potential for insight into other complex sociotechnical systems where performance emerges from multiple system functions. FRAM can be used to investigate how different configurations of functions can lead systems to flourish or stall.

Furniss et al. (2007) outline the need to develop a positive resonance model of human factors practice. The motivation for this was to account for how usability and human factors evaluation methods are adopted and adapted in practice. More specifically, in FRAM terms, this means accounting for how methods are functionally coupled to a broader system of human factors practice. However, at that time it was not obvious how this could be done. Here we focus on how we applied (and slightly modified) FRAM to build up a broader positive resonance model of human factors practice.

\section{Background}

In the early 2000's the underlying models for understanding accidents were criticised as being too simplistic for capturing the multiple parallel factors that contribute to accidents (Hollnagel, 2004; Leveson 2004). This led to the introduction of two methods to try to capture these systemic complexities: Systems-Theoretic Accident Model and Processes (STAMP) (Leveson, 2004) and Functional Resonance Analysis Method (FRAM) (Hollnagel, 2004). This paper focuses on FRAM. This section introduces FRAM and,its published applications, introduces positive resonance, and provides a 
background to the research problem, i.e. to understand usability evaluation method use in human factors practice.

\section{FRAM: An overview}

Hollnagel (2004) presented the Functional Resonance Accident Model (FRAM) as an alternative way of analysing accidents in complex systems, such as incidents in surgery and maritime accidents. He argued that underlying accident models shape our understanding of their causes and appropriate remedial action. He contrasts three different underlying accident models to provide a framing for FRAM:

- Simple linear models assume that a single causal chain of events can be identified. This causal chain can be traced back to its root cause, which can then be addressed to improve safety. For example, the root cause could be an instance of human error and the remedial action might involve disciplining and training the operator. An example of a simple linear model is Heinrich's Domino Model (Heinrich et al., 1980).

- Multi-linear models assume that different causal chains can coalesce to cause accidents. Here a root cause is harder to find as a number of vulnerabilities, which on their own would not pose a threat, could coincide to cause an unwanted event. Here remedial action might look to address active failures that trigger unwanted events and latent conditions that do not prevent the unwanted event from developing. An example of a multi-linear model is Reason's Swiss Cheese Model (Reason, 1997).

- Non-linear models assume that performance is complex, emergent, and intractable as a causal chain. Whereas both linear models look for failures to address and try to eliminate variability, non-linear models assume that 
variability is necessary to cope with the changing demands within and outside of the system. Rather than decomposing the system into components, these models look at the performance variability of different functions in the system and how these interact. Non-linear models include FRAM (Hollnagel, 2004) and STAMP (Leveson, 2004).

FRAM (Hollnagel, 2004) was first proposed as a method to analyse how the functions in a system could resonate together to cause accidents. Here a function is defined as something a system does or the means a system uses to achieve a goal (Hollnagel, 2012a, p. 39-40). A function differs from a component in a system, whereas components describe parts of the system (e.g. air traffic controller, monitor, radio) a functional view describes tasks and activities (e.g. monitor the trajectory of planes, maintain a safe distance between planes, communicate with pilots). FRAM allows one to examine how functions coalesce and impact each other without the need for a strictly linear causal chain of events that led to an accident, so it hopes to capture complex nonlinear interactions (Hollnagel, 2004). FRAM later had a name change to Functional Resonance Analysis Method (Hollnagel, 2012a) to recognise the potential for expanding the scope of the method. This also made it more congruent with arguments that one should understand the normal functioning of a system and not just its failure modes to improve safety (Weick \& Sutcliffe, 2007; Hollnagel, 2014).

Compared to simple linear and multi-linear models FRAM brings very different assumptions to bear on the situation, which impacts how we see the world. Hollnagel (2004) outlines four principles that encapsulate some of the critical assumptions when approaching a problem from a FRAM perspective, which contrast with the other safety models above: 
- Principle of equivalence of success and failure - This moves away from the notion that failure is somehow a qualitatively different mode to success. Instead normal functioning of a system is reliant on appropriate adaptations to fluctuations in demands and disturbances; failure is the temporary or sustained absence of the ability to make appropriate adjustments.

- Principle of approximate adjustments - This is in contrast to fairly simple static systems where appropriate behaviour can be easily specified. Instead the view of the system is complex and underspecified so adjustments are necessary to decide on appropriate courses of action. Furthermore, competing goals may mean that appropriate trade-offs are only clear with hindsight (Hollnagel, 2012b)

- Principle of emergence - Performance cannot be attributed or explained by only referring to components of the system; instead performance is assumed to emerge across the system. The variability of functions can interact in such a way that small changes can have disproportionally large effects, which is a marker of non-linear systems.

- Principle of functional resonance - Functions within a system will be related to each other and work together to achieve overall system goals. Multiple functions can resonate to exacerbate the performance variability of each other, causing normal limits to be exceeded. This can happen in expected and unexpected ways.

Central to FRAM is the idea of resonance which Hollnagel $(2004$, p160) introduces using the example of a swing. Children quickly learn that they need to push a swing at the right time to make it go higher. By doing this their energy amplifies the motion of the swing, i.e. their push resonates with the swing. In contrast to this intended action stochastic resonance can be described as noise in a system that can be quite 
unpredictable and enhance or decrease signals depending on its variance, e.g. a freak wave can be very rare and large, and can be understood in terms of a number of variables resonating together (Hollnagel, 2004, p165). Functional resonance captures how functions are interconnected and can influence the performance variability of each other (Hollnagel, 2004, p170).

FRAM (Hollnagel, 2004, 2012a) identifies what functions there are in a system, examines their potential variability, defines how they may resonate, and seeks to manage performance variability. It focuses on control and dampening variability so that the performance of a system remains predictable, and within the boundaries of safe performance. For example, Hollnagel (2012a) describes the Herald of Free Enterprise Car Ferry Disaster in terms of FRAM. The three main functions involved in the disaster were: 1) <leave harbour $>$ which was running late which added time pressure elsewhere in the system and meant the ferry left before it was ready to go to sea; 2) $<$ close bow doors $>$ which was an omitted step; and 3) $<$ man harbour stations $>$ which was incomplete as not all habour stations were manned that impacted monitoring and supervisory performance. The variability of these and other connected functions led the ferry to sink. Understanding the variability allows one to think about suitable interventions to reduce the likelihood of this and similar accidents in the future. Figure 1 depicts the performance variability of different functions in a system - these are the lines with different frequencies and amplitudes. Where some functions resonate, their amplitude increases, so variability increases. Where this is dramatic it can compromise quality margins and even exceed the span of control. In these most extreme cases the system's performance becomes out of control. The unpredictable nature of this form of variability can lead to accidents, e.g. leading a ferry to sink. So, in this model high 
amplitude and variability is generally unwanted as dramatic increases can threaten control and safety.

[Insert Figure 1 about here]

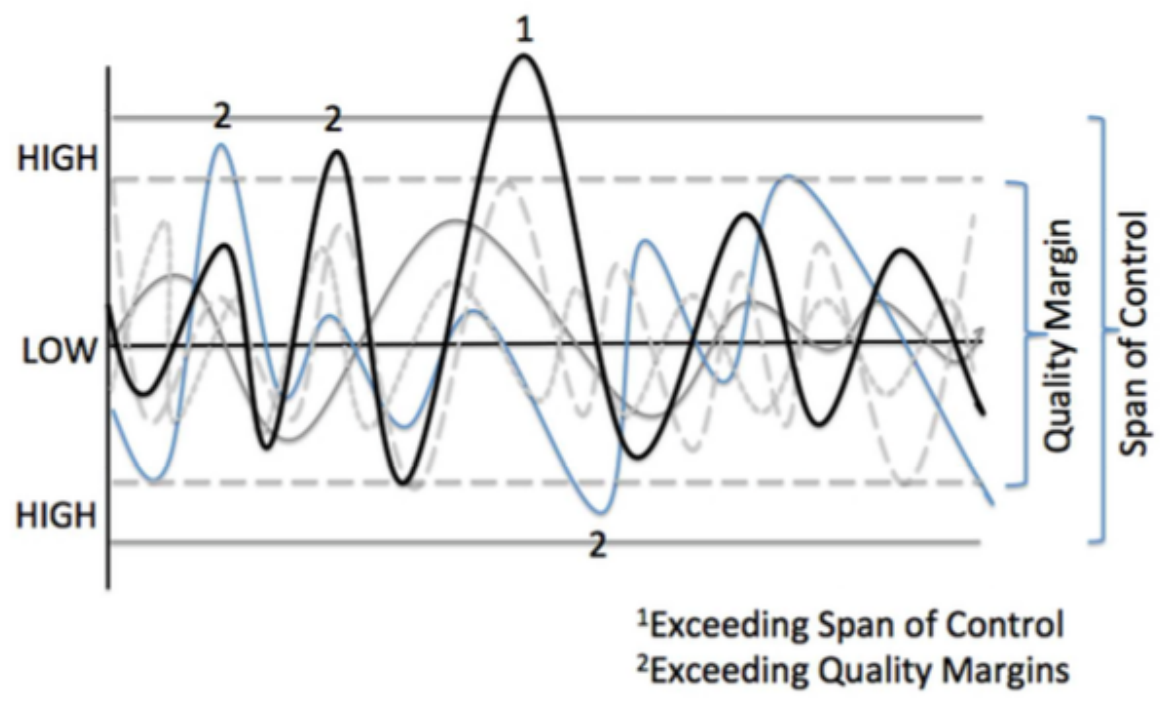

Figure 1: Performance variability of functions (from high to low) against time. Each faint wavey line represents the output of a function, whereas the bold line represents the summative effect of these outputs (adapted from Dijkstra, 2006, p. 97). $250 \times 153 \mathrm{~mm}(72 \times 72 \mathrm{DPI})$

\section{Applications of FRAM}

Published applications of FRAM mainly focus on near miss and accident analyses (e.g.

Nouvel et al., 2007; Hollnagel et al., 2008; Herrera \& Woltje, 2010; De Carvalho, 2011)

and risk and safety assessments (e.g. Lundblad et al., 2008; Woltje \& Hollnagel, 2008;

Belmonte et al., 2011; Pereira, 2013). Another study reports adapting the FRAM

technique for hazard analysis (Frost \& Bo, 2014); here three scenarios are considered for an airline's operations control centre and hazards are identified between subsystems, systems outside of the boundary of the system under study, and in relation to latent functional design hazards. These studies provide insights into understanding how normal variability, which is unproblematic most of the time, can suddenly resonate with variability in other functions to unsafe levels, which is different to traditional methods that focus on establishing who did what and when in a causal chain (Herrera \& Woltje, 2010). These studies cover safety issues in aviation, railway and healthcare. We have 
not identified any application of FRAM outside safety. The main point of interest of these studies with respect to Figure 1 is where the performance variability stretches across quality margins and the span of control; however, normal performance needs to be understood to gauge how the system remains within these bounds most of the time.

Pereira (2013) expanded the scope of FRAM to include aspects of effectiveness rather than solely focusing on safety issues. For example, they report issues like delays and ineffective use of materials, time and effort in preparing radioactive substances for healthcare purposes. Pereira's treatment of effectiveness focuses on a loss of effectiveness in the system. In our study, from a positive resonance perspective, we also want to consider gains in effectiveness, i.e. what actions and configurations will allow the system to flourish?

\section{A turn to positive resonance}

There is little guidance and support for using FRAM to examine successful outcomes. Hollnagel (2012a, p. 87) states that uncontrolled performance variability can result in positive outcomes, which should be facilitated and enhanced, but this is not developed further. Furthermore, there are no published examples we could find that consider gains in effectiveness. We turn to positive resonance to focus more on effective processes and successful outcomes.

Just as FRAM is suited to understanding how a network of functions are related and how performance variability emerges from these relationships, so it has potential for exploring the tangled layered network of functions of adaptive systems and how they stall and flourish: 
"In tangled layered networks, because of extensive interdependencies in time, space, functions, and scale, changes will produce multiple effects that go beyond those intended. In some cases (A), change directed only at one unit or role within the system will trigger inadvertently deleterious effects on other aspects of the system that cancel out or outweigh the intended benefits. In other cases (B), changes in one area will tend to recruit or open up beneficial changes in many other aspects of the network. To the degree (A) occurs, stalls follow; to the degree (B) happens, florescence begins." David Woods on Fluorescence (personal communication)

By linking these ideas from Woods to the structure of FRAM we open up the theoretical and empirical scope of the method. Beyond dampening uncontrolled performance variability and safety concerns, there is potential for a novel approach to use FRAM to investigate how sociotechnical systems stall and flourish. We propose positive resonance to describe how functions positively resonate to maximise performance under constraints and variable conditions.

Positive resonance provides the extra push to influence and impact other functions, similar to the metaphor of the child's swing described above. The child's swing is intuitive, one-dimensional and easy to conceptualise. More challenging is multidimensional positive resonance that leads to emergent system performance. To illustrate we use an example from competitive team sport: a football team signs a new central midfielder who seems to have a positive impact on the whole team, which translates into better results. He holds the ball better than his predecessor which buys his team mates more time; he passes the ball well so the team's wingers are able to attack the opposition better (this stretches and tires the opposition's defence); he can spot creative passes that exploit the pace of the team's forward players who run behind the opposition's defence; and he is experienced and able to nurture and advise younger team players. Here the new signing positively resonates with the rest of the team across 
many dimensions, amplifying the potential performance of other players in the short and the longer team. Here a healthy push at the right time, where multiple functions positively resonate, provides potential for the system, or the team, to perform better than the sum of its parts.

This turn to positive resonance can be visualised in Figure 2 by re-labelling the boundaries to 'normal' quality margins and 'normal' spans of control. We are interested to understand how a system cannot only behave reliably but also effectively within normal quality margins and spans of control. However, they could also exceed these boundaries, which could exceed expectations. Positive resonance does not mean that uncontrolled performance variability increases; rather, it means that it amplifies the effectiveness of the system.

[Insert Figure 2 about here]

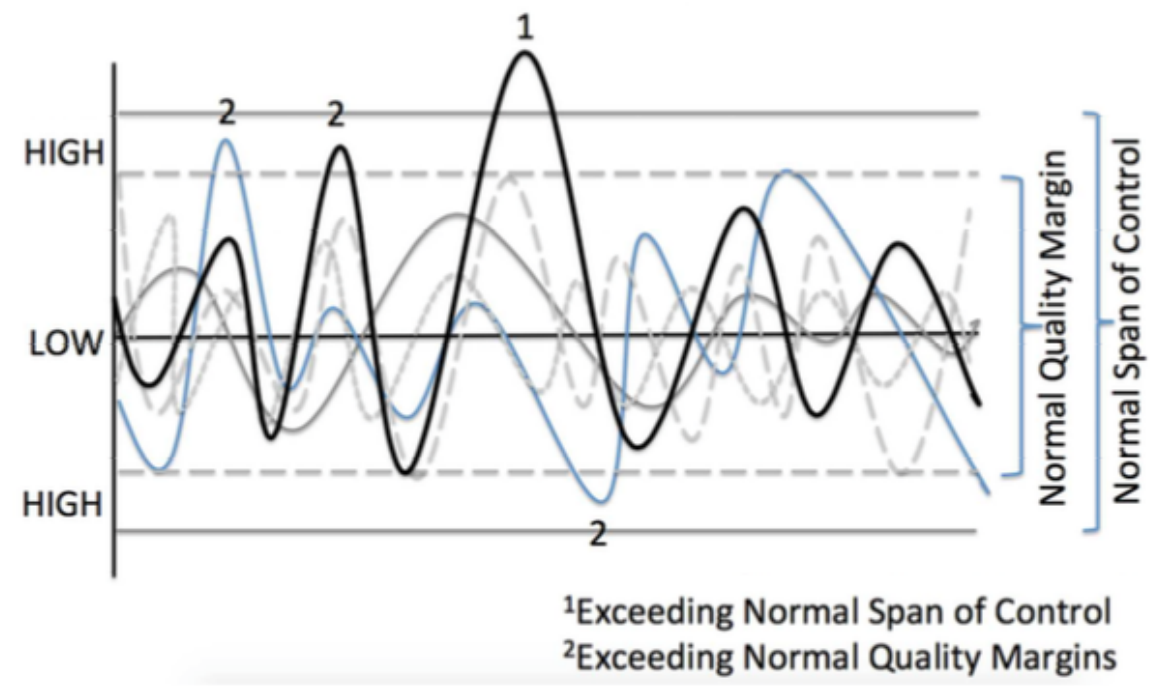

Figure 2: Performance variability of functions (from high to low) against time. Each faint wavey line represents the output of a function, whereas the bold line represents the summative effect of these outputs. Functions can exceed normal margins of quality and control. $398 \times 237 \mathrm{~mm}(72 \times 72$ DPI $)$

We use FRAM to explore how functions in human factors practice positively impact each other to create effective processes and quality outcomes. 


\section{Understanding human factors practice and usability evaluation methods}

An important part of human factors research has been to enhance techniques, solutions, tools and methods so that engineering computer systems can be improved in practice (Newman, 1994). A large part of these efforts has been in the development and testing of usability evaluation methods and techniques, e.g. heuristic evaluation (Nielsen \& Molich, 1990), think aloud protocol (Boren \& Ramey, 2000), and cognitive walkthrough (Wharton et al., 1994). This has attracted high profile criticisms to approaches and assumptions underlying the work (Gray \& Salzman, 1998; Wixon, 2003; Hornbæk, 2010); comparison studies of different methods (e.g. Hartson et al., 2003; Blandford et al., 2008); comparison of different forms of methods (e.g. OlmstedHawala et al. 2010); case studies of method adoption and appropriation (e.g. John \& Packer, 1995; Spencer, 2000; Blandford et al., 2006; Berndt et al., 2014); studies of method use in practice (e.g. Nørgaard \& Hornbæk, 2006) and new conceptions of what 'methods' actually mean (e.g. Woolrych et al., 2011).

Motivated by the criticism that research on methods was not relevant to practitioners (Wixon, 2003), we asked practitioners what is relevant to method use in practice. Over an extended qualitative study we first built up a picture of the important dependencies using Grounded Theory, which was then complemented by analyses using Distibuted Cognition and Resilience Engineering (Furniss et al., 2011). This culminated in describing factors that lie upstream and downstream of method use using FRAM. We found that to understand method use in practice we needed to understand the context in which they are embedded. Consequently, we developed a FRAM model of human factors practice, within which methods are embedded. We present the application of FRAM and the development of the positive resonance model of human factors practice below. 


\section{Method}

This section focuses on the application of FRAM to describe method use in a system of human factors practice. The methodology for the extended qualitative study is reported in Furniss et al. (2011).

\section{Sampling}

22 practitioners were interviewed. 9 worked in usability predominantly applying evaluation and design methods to websites and other interactive media and technologies (these participants were coded from W1 to W9). 13 worked in the area of human factors applying human factors evaluation methods to transport, energy production, healthcare and other safety related contexts (these participants were coded from S1 to S13). Practitioners from these domains were chosen as related but contrasting communities to broaden the scope of our data and resultant analysis - in keeping with theoretical sampling (Chamberlain et al., 2004). We were interested in both the informal usability methods and practices of the usability professionals' domain and the formal methods and practices of the safety domain. Seven participants had 1-5 years of experience, nine participants had over 5 years of experience, and six participants had over 10 years of experience. Six participants had experience of working in-house dealing with internal clients, and sixteen participants had experience of working in consultancies dealing with external clients.

\section{Data gathering}

The semi-structured interviews lasted about an hour each and were guided by five different topics: (1) the background of the interviewee; (2) the structure of the organisation and the sort of work they are involved in; (3) who they work for, what drives their work and what they aim to deliver; (4) their role and the skills they need to do their job well; and (5) what tools, methods and techniques are used, how they are used, when they are used and what is valued in a good technique. All participants consented to having the interviews recorded. All the interviews were transcribed and anonymised. 


\section{FRAM Analysis}

We outline the four main steps to using FRAM, preceded by a preparation step (Step 0), as described by Hollnagel (2004; 2012a).

\section{Step 0: Recognise the purpose of the FRAM analysis}

This preliminary step is to make the purpose of the FRAM analysis clear. This could have implications for how the next four steps are conducted, e.g. there are slight differences in how the method is used for event investigation and for risk analysis (Hollnagel, 2012a, p.36). For example, for an event investigation 'activities' should be used to focus on what actually happened. 'Activities' describe how work is actually done or what happens (Hollnagel, 2012a, p. 39). In contrast 'tasks' describe how work should proceed and is aligned to how work is imagined. A risk analysis could use either; it makes a difference whether idealised functions are used in 'tasks' or actual functions are used as part of 'activities'.

\section{Step 1: Identify and describe the functions}

The first step in a FRAM analysis is to identify and describe the normal system functions required for everyday work to succeed. In FRAM, a function is the means to achieve a goal (Hollnagel, 2012a, p. 39-40). In other words it is the tasks or activities that are performed to achieve a certain aim. For example, <enter pin number $>$ and $<$ collect money $>$, are functions involved in using a cash machine. They contain verbs because they describe what is being done (Hollnagel, 2012a, p. 54).

Identifying functions should proceed from a description of the system. A FRAM analysis does not describe detailed sequential steps like a Hierarchical Task Analysis would (e.g. $<$ insert card $>$, < press $1^{\text {st }}$ digit of pin $>$, $<$ press $2^{\text {nd }}$ digit of pin $>$, $<$ press $3^{\text {rd }}$ digit of pin>, <press $4^{\text {th }}$ digit of pin>, < press enter>, etc.), but a set of functions to achieve a goal (e.g. <insert card $>,<$ enter pin number $>,<$ specify amount to withdraw $>$, $<$ collect money $>,<$ retrieve card $>$ ) (Hollnagel, 2012a, p. 41). Functions can be at 
different levels of granularity, from an individual to an organisation. Functions can refer to what a technology does, or what joint units of people and technology do together. Functions do not need to be described in sequence.

Each function has six different 'aspects' that shape how functions can be related or coupled when using this method, i.e. the output of one function might impact the resources or be a precondition of another (Hollnagel, 2012a, p.46):

- "Input (I): that which the function processes or transforms or that which starts the function.

- Output (O): that which is the result of the function, either an entity or a state change.

- Preconditions (P): conditions that must be exist before a function can be carried out.

- Resources (R): that which the function needs when it is carried out (Execution Condition) or consumes to produce the Output.

- Time (T): temporal constraints affecting the function (with regard to starting time, finishing time and duration).

- Control (C): how the function is monitored or controlled."

These aspects will start to define the potential variability of the function and how functions are related. Aspects are described as states (Hollnagel, 2012a, p. 54-55), e.g. 'pin code entered' or 'cash retrieved'. 
Functions can lie upstream and downstream from other functions in a temporal manner, and functions can be foreground or background functions to denote the importance of their active role in the analysis.

\section{Step 2: Determine the potential for variability}

Functions will vary in how they are performed, i.e. they do not just succeed or fail

(Hollnagel, 2012a, p. 53). For example, they could be rushed if there is a lack of time, they could be underpowered if there is a lack of resource, there could be a delay, etc. This variability can impact the output of the function and so impact aspects of other functions in the system, and so uncontrolled performance variability spreads if it is not corrected, dampened or absorbed. Thinking back to the three functions in the ferry disaster referred to earlier: it was running late so it was not ready for sea and the process was rushed, people had not manned all the harbour stations which made the mistake of not closing the bow doors go unnoticed until it was too late.

Hollangel (2012a, p. 64) describes three sources of variability for functions: internal, external and upstream-downstream coupling. These can be considered for functional performance. A brief example: a person's performance may vary because they are tired (internal variability); they may work in a company that has a poor safety culture where other people commonly cut corners (external variability); they may be new, also working with a supervisor who is new, then encounter something untoward whilst a more experienced team member is on his break (upstream-downstream coupling). FRAM's forte is in understanding how a network of functions are related and how performance variability emerges from these relationships, which engages with this last type of variability. 
To examine the actual and potential variability of functions, Hollnagel $(2004$, p. 191) proposes a checklist for identifying the context dependent common performance conditions (CPC) of the function. For each function this covers: availability of resources, training and experience, quality of communication, Human-Machine Interface (HMI) and operational support, access to procedures and methods, conditions of work, number of goals and conflict resolution, available time, circadian rhythm, crew collaboration quality, quality and support of organisation. The variability of each of the CPCs should be considered, described and graded.

\section{Step 3: Define functional resonance}

This step moves beyond how individual functions vary to assess how they may be related and influence each other. Here the idea of functional resonance comes into play, i.e. how functions that have some sort of functional upstream or downstream coupling influence each other's performance variability. The different aspects should be attended to, to establish how functions are coupled and whether this coupling is likely to increase or decrease variability.

FRAM's graphical notation can help track and identify links between functions' aspects. The functions in a FRAM network are represented as hexagons. Each corner represents one of the six aspects as shown in Figure 3.

[Insert Figure 3 about here] 


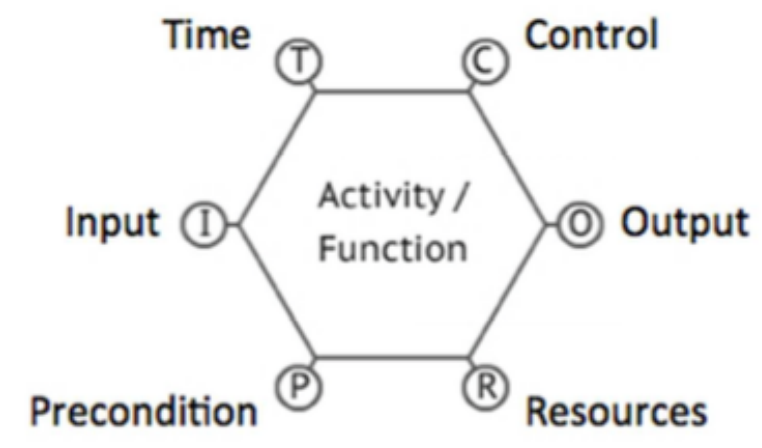

Figure 3: A function and its six aspects.

$115 \times 71 \mathrm{~mm}(72 \times 72$ DPI)

In a FRAM visualisation multiple hexagons can be displayed together, and lines that link one aspect to another show how the functions are coupled (Figure 4). The FRAM Model Visualiser software tool has been developed to help build FRAM networks, and track functions and their aspects (Hollnagel \& Hill, 2015).

[Insert Figure 4 about here]

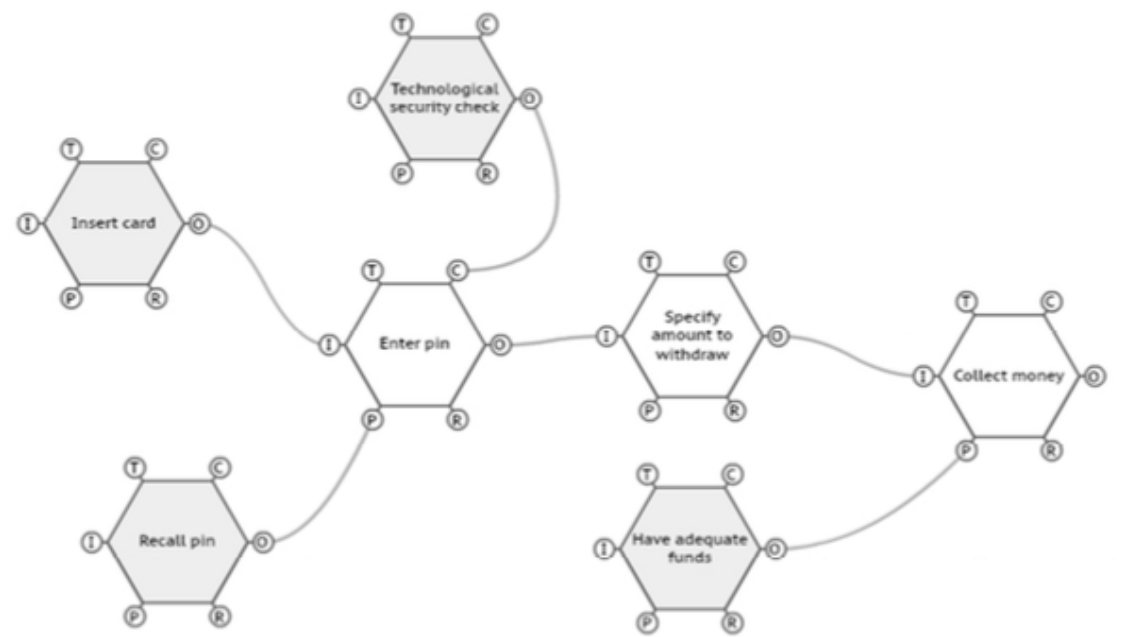

Figure 4: An example of how functions can be coupled, represented in FRAM's visual notation, using the FRAM Model Visualiser tool. The tool automatically greys out functions that only have one connection as they are likely to be a background function. $282 \times 171 \mathrm{~mm}(72 \times 72 \mathrm{DPI})$

Step 4: Managing performance variability

Hollnagel (2012a, p. 87) describes this step as the opportunity to monitor and manage possible occurrences of uncontrolled performance variability in the system. Typically, 
this would involve measures to dampen performance variability and to monitoring critical couplings. However, where variability leads to positive outcomes the purpose is to facilitate and enhance this potential without losing control. We report examples of positive and negative resonance so it can be understood, enhanced and/or dampened.

\section{Respondent Validation}

We conducted a further step over the basic FRAM process: respondent validation. It is particularly useful where qualitative processes include complex and creative moves between theory, data and new ideas (Furniss et al., 2011). We invited practitioners who had been involved in the original study, together with further practitioners who had not, to assess the model that we developed using FRAM This was done by emailing them a summary of the overall model, six subsystems and 29 functions for feedback. We asked whether the model was generally accurate, whether there were any important elements missing, and whether we had included elements that were not significant. We received responses from 10 of the 22 participants in the study, and from 8 practitioners who were not involved in the original interviews (this latter group were coded from E1 to E8).

\section{Results: Applying FRAM}

We report our experience of applying FRAM following its four steps, plus the preparation and validation steps, and highlight results of the analysis at each stage. However, the process of applying FRAM was not as linear as these steps suggest. For example, identifying functions in Step 1 involved brainstorming and drawing preliminary FRAM network diagrams associated with Step 3, then iterating the list of functions and the diagrams.

\section{Step 0: The purpose of the FRAM analysis}

FRAM's focus on system variability suggested it had potential to be used to explore the different activities in human factors project work and practice. However, this was not an 
accident analysis or risk assessment, and our focus was not on human factors projects spiralling out of control or resulting in unwanted events. Instead, the purpose of this analysis was to assess how practitioners organised their work to positively resonate with the project and the context so that it could flourish. For example, practitioners would encourage clients to watch usability testing directly as this was more convincing than reading the results in a report second-hand and it speeded the delivery of the results.

\section{Step 1: Identify and describe the functions}

We identified the main goals and functions of the system by identifying patterns in the qualitative data. For example, many practitioners described projects they had been involved in and the different stages of those projects. The functional analysis was not limited to these purely procedural functions but could include a wide range of factors that functionally affected the system. Consequently we included in the FRAM model: the development and selection of reporting practices, the development of understanding, tool development, persuading others, and building a reputation.

Overall, we identified 29 functions using FRAM (see Table 1). To facilitate capturing the different aspects for each function we created a template (see Figure 5 parts A and B). Each function is numbered so that it can be cross-referenced between the descriptive templates, the FRAM network diagrams, tables, etc. Table 2 shows the first three functions and their summary description to illustrate the nature of these functions. We show a full description of an example function in Figure 6.

Each function was derived from the aggregated picture that was given by the interviewees across their different projects. In this sense the resultant FRAM model we have developed is a general view of human factors project work rather than a detailed view of any particular project. As an example, Figure 6 shows how the function 
'Human Factors practitioner develops understanding of client need' is grounded in the

data and supported by direct quotations from participants W5, W8 and S5.

[Insert Table 1 about here]

F Table 1. The 29 functions of human factors project work using FRAM.

\begin{tabular}{|l|l|}
\hline No. & Name of Function \\
\hline 1. & Client recognises a need \\
\hline 2. & Practitioner develops understanding of client need \\
\hline 3. & Develop work packages \\
\hline 4. & Negotiate project \\
\hline 5. & Client develops an understanding human factors processes \\
\hline 6. & Allocate resources \\
\hline 7. & Develop methods \\
\hline 8. & Select method \\
\hline 9. & Develop tools \\
\hline 10. & Select tool \\
\hline 11. & Human factors practitioners are developed \\
\hline 12. & Senior human factors practitioners manage project work \\
\hline 13. & Perform project work \\
\hline 14. & Develop a paper trail \\
\hline 15. & Persuade client \\
\hline 16. & Develop reporting practices \\
\hline 17. & Select reporting practice \\
\hline 18. & Analyse data \\
\hline 19. & Practitioner develops an understanding of the project issues \\
\hline 20. & Practitioner develops understanding of the domain \\
\hline 21. & Write report \\
\hline 22. & Communicate to client \\
\hline 23. & Client engages with results \\
\hline 24. & Client develops an understanding of the results \\
\hline 25. & Client considers results \\
\hline 26. & Client acts on results \\
\hline 27. & Build reputation \\
\hline 28. & Build rapport \\
\hline 29. & External audit of project work \\
\hline & \\
\hline
\end{tabular}

[Insert Table 2 about here]

Table 2. First tbree functions in FRAM model and their summary descrintion.

\begin{tabular}{|r|l|l|}
\hline No. & Name of Function & Description \\
\hline 1. & $\begin{array}{l}\text { Client recognises a } \\
\text { need }\end{array}$ & $\begin{array}{l}\text { Clients vary in their maturity, attitude and knowledge } \\
\text { toward human factors. They will have different } \\
\text { resources, processes and constraints. They will seek } \\
\text { human factors services for different reasons e.g. } \\
\text { financial, product quality, performance and legislative } \\
\text { reasons. }\end{array}$ \\
\hline 2. & $\begin{array}{l}\text { Practitioner } \\
\text { develops } \\
\text { understanding of } \\
\text { client need }\end{array}$ & $\begin{array}{l}\text { Clients will recognise a need but will have a varied level } \\
\text { of understanding about the underlying human factors } \\
\text { issues contributing to their problems. Elaborating and } \\
\text { clarifying the need to be addressed in the project can be } \\
\text { a major piece of project work. Some clients will be quite } \\
\text { knowledgeable about what they expect from a project } \\
\text { and how it should be performed. Others may not want to } \\
\text { understand their need too much and are happy taking a } \\
\text { 'hands off' approach as they just want the problem to be } \\
\text { solved. }\end{array}$ \\
\hline 3. & $\begin{array}{l}\text { Develop work } \\
\text { packages }\end{array}$ & $\begin{array}{l}\text { Over time practitioners build up a repertoire of work } \\
\text { packages that can be tweaked and combined for client } \\
\text { projects. This tweaking can include changing methods, } \\
\text { or changing test plans, objectives, scenarios, and users } \\
\text { within the same method. These pro-forma work } \\
\text { packages organise knowledge and improve efficiency. }\end{array}$ \\
\hline
\end{tabular}




\section{Step 2: Determine the potential for variability}

In the next step, we reviewed the context dependent common performance conditions (CPC) of each function using the template shown in Figure 5. Instead of grading the variability of each condition as suggested by Hollnagel (2004, p. 193) the important conditions are only highlighted (represented in Part $\mathrm{C}$ of the template in Figure 5). The analyst chose not to go to this level of detail as $11 \mathrm{CPC}$ ratings for each of the 29 functions meant over 300 specific ratings with poor anticipated benefits for the costs. Instead, the key ones were highlighted for each function and each CPC was commented on. This built up a qualitative picture of the factors affecting the variability of the function.

Steps 1 and 2 were further elaborated and supported by the qualitative data, which appears in Part D of the template in Figure 5. Figure 6 shows how this template was used.

[Insert Figure 5 about here]

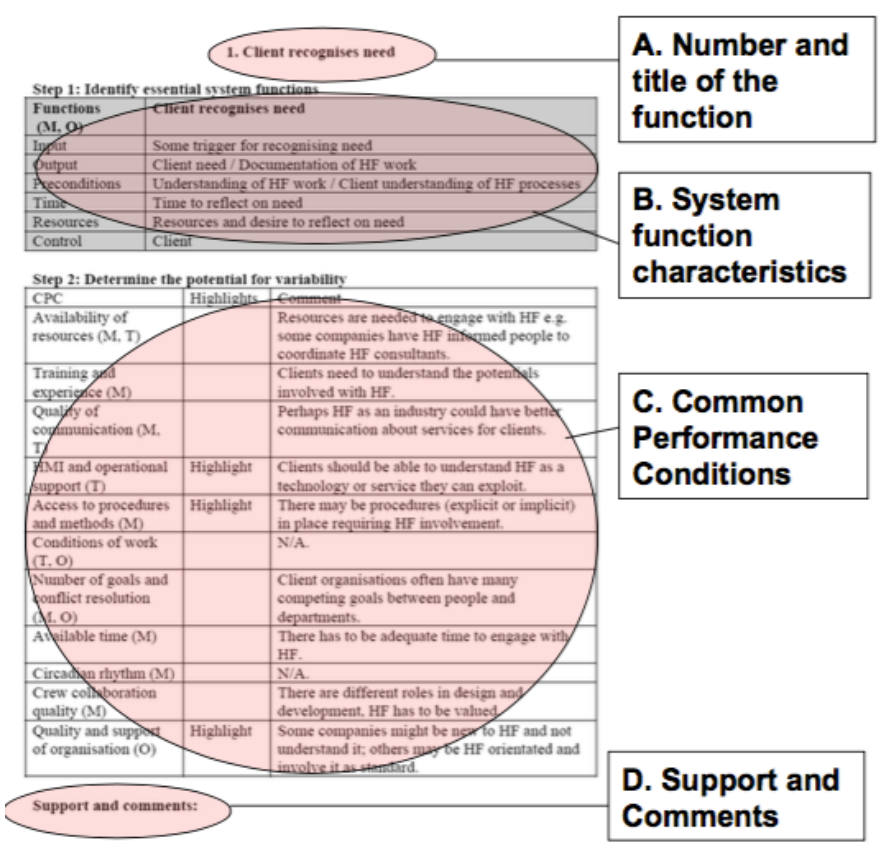

[Insert Figure 6 about here] 


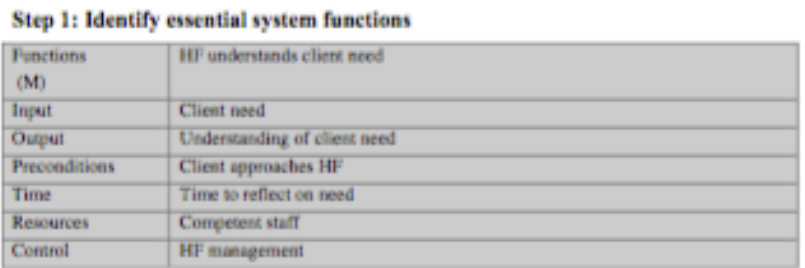

\begin{tabular}{|c|c|c|}
\hline CFC & Hignighes & Commens \\
\hline $\begin{array}{l}\text { Availability of resoufves } \\
(\mathrm{M}, \mathrm{T})\end{array}$ & Hignighte & 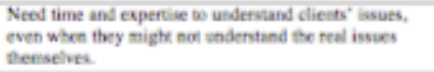 \\
\hline $\begin{array}{l}\text { Training and experience } \\
\text { (M) }\end{array}$ & & $\begin{array}{l}\text { Experience is needed so understand ind translate inte HF } \\
\text { issues. }\end{array}$ \\
\hline $\begin{array}{l}\text { Quality of commenicasion } \\
(\mathrm{M}, \mathrm{T})\end{array}$ & & Imporiark so both portics undereand each other. \\
\hline $\begin{array}{l}\text { HMi and operitional } \\
\text { support (T) }\end{array}$ & & $\mathrm{N} / \mathrm{A}$ \\
\hline $\begin{array}{l}\text { Access to proondires and } \\
\text { mechods (M) }\end{array}$ & & 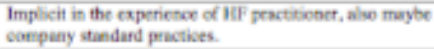 \\
\hline Condicons of woek $(T, 0)$ & & $\mathrm{N} / \mathrm{A}$. \\
\hline $\begin{array}{l}\text { Nunber of goals and } \\
\text { coeffict resolutice (M, O) }\end{array}$ & & 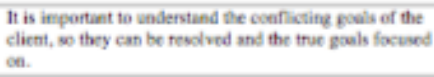 \\
\hline Available time (M) & & Need time to understand cliens issues. \\
\hline Cincadian flyom (M) & & N/A. \\
\hline $\begin{array}{l}\text { Crew collaborision } \\
\text { quality (M) }\end{array}$ & & Need time with, and aceess bo, key stakchoisers. \\
\hline $\begin{array}{l}\text { Quality asd sipport of } \\
\text { efgatisation ( } \mathrm{O})\end{array}$ & & $\begin{array}{l}\text { If exluare of be compary values IIF then they will be } \\
\text { given mere time and antentien. }\end{array}$ \\
\hline
\end{tabular}

\footnotetext{
Support and comments:

The straightforward ease is that a client has recognised a need that is clearly translated into HF/usability terms and so the project ean be planned. However, there are more compticated scenarios. For example, where the elient doesn't know their need:

" $R$ : Yeah, it would range... well the unspoken assumption behind that question is that all the clients know why they have come to us, and they don't, sometimes the bigest portice of our job is to wotk with them to figure that can." WB
}

\section{Step 3: Define functional resonance}

We built the FRAM network from the functions identified in Step 1. Relating codes to each other was aided by reviewing their six aspects, e.g. the client allocating enough resources is a precondition for agreeing to a particular project. Reviewing the six aspects revealed gaps in the model, which led to further questions for the data. For example, the 'control' aspect encouraged us to think about supervisory mechanisms and their influence, which we had not done previously. We realised from this that the human factors practitioner was a key resource for most system functions, and their senior managers performed a supervisory role for most functions in the system. Consequently, this led to more functions being derived from the data, e.g. $<$ Human factors 
practitioners are developed $>$ and $<$ Senior human factors practitioners manage project work>.

The development of a meaningful and useful FRAM network was non-trivial. For simple networks with less than five or six functions it would be easier, but 29 functions, with six aspects each, meant we were overwhelmed. We used the FRAM Model Visualiser to help us track all of these functions and aspects, but there were so many links that the visual form of the network was unintelligible even after hiding less significant lines and rearranging functions (see Figure 7). We were aiming for a meaningful and useful FRAM network: firstly so that it could provide further insight into the data for ourselves (within the research team) and secondly so that we could use it to communicate to others, e.g. for respondent validation (outside the research team). [Insert Figure 7 about here]

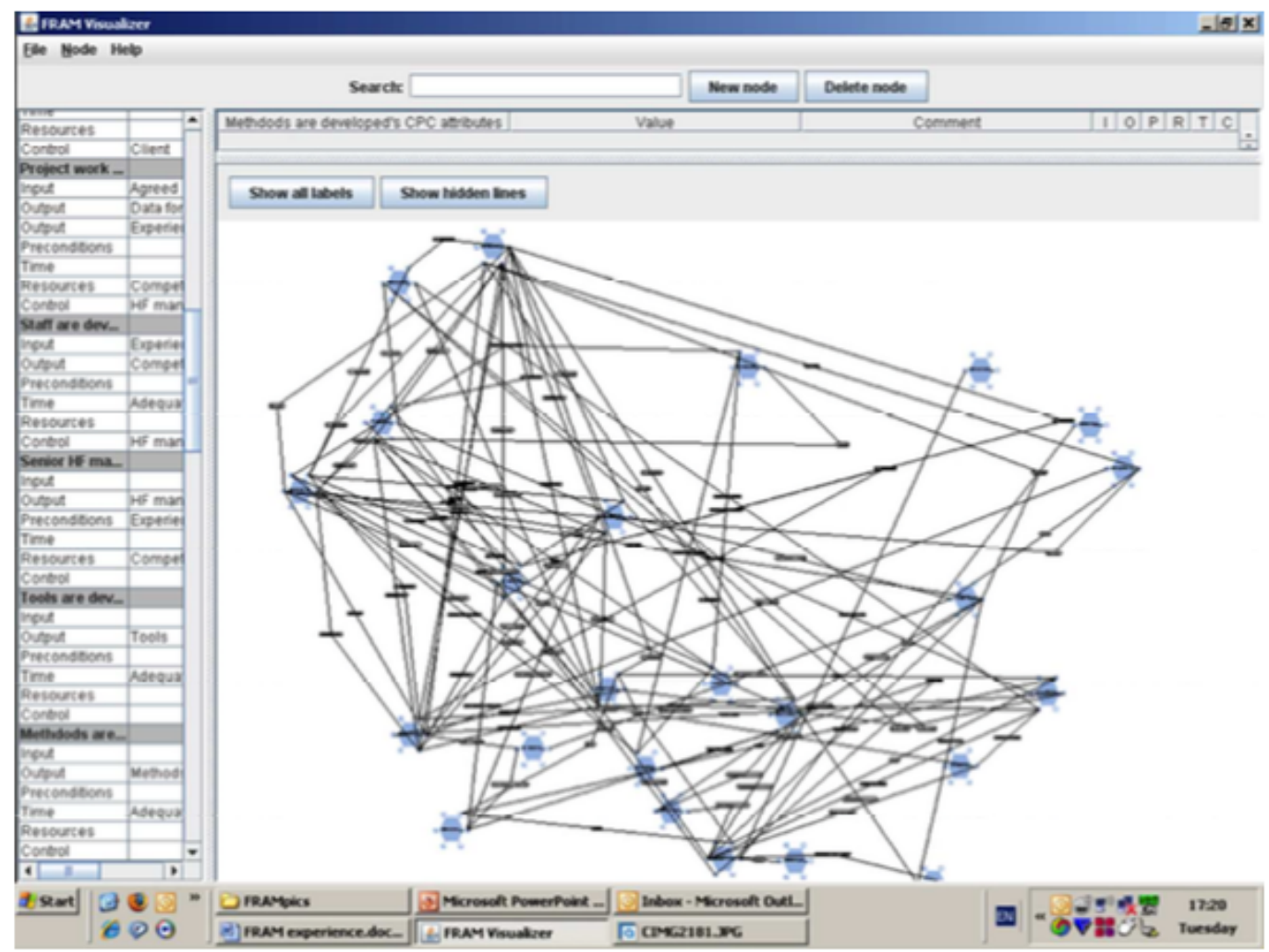

Figure 7: FRAM Model Visualiser screenshot. 
Through sketching FRAM networks with pen and paper, to using PostIt notes cut into hexagon shapes, to diagramming with PowerPoint and Visio software tools, we iterated the visual form of the network. Each iteration tried to simplify the network and make it more intelligible. Once it was more intelligible we could see features of the network, e.g. reinforcing loops between a practitioner choosing a method, using that method, learning more about that method through its use, and then being more likely to select it again in the future because they are more familiar with it. This loop created stability and inertia in the system.

The requirement to make the representation intelligible to participants for our respondent validation encouraged us to think hard about how we might present it. Essentially we needed another level of abstraction or summary to make the model more accessible to practitioners who would be asked to provide feedback on our results. This led us to recognise six sub-networks in our FRAM model:

(1) Central project process - this is a mainly linear network of functions involved in the stages of project work. They lead through from $<$ Client recognises a need $>$ to $<$ Practitioner develops understanding of client need $>$ to $<$ Develop work packages $>$ to functions involved in negotiation, method use, analysis, report writing, and communication.

(2) Analytic insight and project understanding- this network is about tackling the issues that the project is engaging in. This starts with the function $<$ Practitioner develops understanding of client need $>$ then has a strong triad between $<$ Practitioner develops understanding of the project issues $>$, $<$ Project work performed $>$, and $<$ Analysis of the data $>$, which reinforce each other. 
(3) Enhancing persuasion, rapport and reputation - this network links functions where there is client contact, which allows the opportunity for the practitioner to build rapport; links functions where decisions need to be made or information is to be communicated so that the practitioner can be persuasive; and links functions where project work is reviewed and evaluated so that a reputation can be built.

(4) Managing staff development and supervision- this network recognises that human factors practitioners are a key resource for all of the project work in the system, and that senior staff are a control function in the system as they supervise and oversee the quality of work.

(5) Evolution of tools, methods and reporting practices - this network links functions where tools, methods and reporting practices are selected for use in projects; to their use in projects and the potential for them to be appropriated and developed in that use. It also links the development of tools, methods and reporting practices to processes outside projects, e.g. the development of methods in academia.

(6) Managing documentation and auditing - this network links all of the functions that generate documentation with the function $<$ Develop a paper trail $>$ and $<$ External audit of project work $>$. The description of this network also recognises documentation as a resource for practitioners to reuse, e.g. in the form of templates for presentations and reports and to gain insights from past projects that are similar to their current ones.

The six sub-networks provided us with an analytic structure to introduce the entire network to respondents in increments. However, it also provided us with extra insight into the system, i.e. there was a central project process and important functional 
networks impacted this. We realised that FRAM itself, and its tools, should support the development of sub-networks to encourage meaningful insight from complex networks.

The full FRAM network is shown in Figure 8. The central project process functions are highlighted in yellow and connected by lines to show how they are functionally coupled. The other lines between functions are hidden via a coding scheme next to each function, e.g. A1 goes to A2, and B1 goes to B2, etc., which is detailed in Table 3. This coding scheme hides the many lines connecting the different functions that would make the network too dense and difficult to read. $\mathrm{H} 1$ to $\mathrm{H} 2$ has been highlighted in green because it has a pervasive impact on the whole system, i.e. human factors practitioners are develop their expertise and experience and act as a resource for many project functions. Similarly, J1 to J2 has been highlighted in orange because it too has a pervasive impact on the whole system as senior human factors practitioners are a supervisory control for many project functions.

[Insert Figure 8 about here]

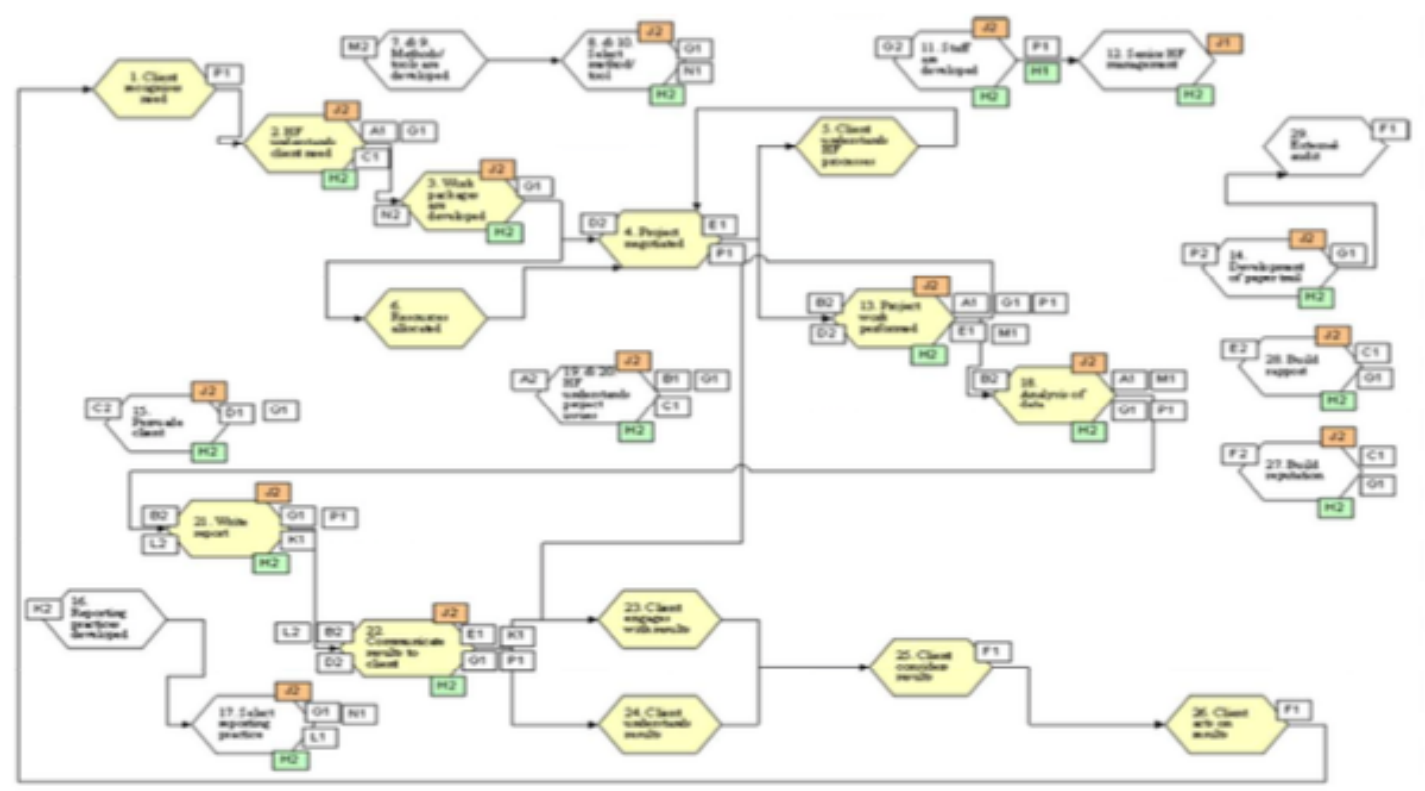

Figure 8: Positive resonance model of human factors practice. 
[Insert Table 3 about here]

Table 3. Codes for functional coupling in human factors practice.

\begin{tabular}{|l|l|}
\hline Code & Coupling \\
\hline A1-A2 & The HF/usability practitioner gains a better understanding of the project issues. \\
\hline B1-B2 & A better understanding of the project issues informs further functions. \\
\hline C1-C2 & $\begin{array}{l}\text { The client is further persuaded through knowledge, understanding, reputation and } \\
\text { rapport. }\end{array}$ \\
\hline D1-D2 & Persuading the client impacts on the work performed and communicating the results. \\
\hline E1-E2 & Rapport is developed through client contact. \\
\hline F1-F2 & Reputation is developed through evaluation of HF/usability work and results. \\
\hline G1-G2 & $\begin{array}{l}\text { Performing HF/usability project functions leads to the development of HF/usability } \\
\text { staff. }\end{array}$ \\
\hline H1-H2 & HF/usability practitioners are a resource for HF/usability project functions. \\
\hline J1-J2 & Senior HF/usability practitioners manage and control HF/usability project functions. \\
\hline K1-K2 & Reporting and communicating results leads to development of practice. \\
\hline L1-L2 & Reporting practices are selected. \\
\hline M1-M2 & Project work leads to the development of methods and tools for practice. \\
\hline N1-N2 & $\begin{array}{l}\text { Selections of methods, tools and reporting practices feed into the development of } \\
\text { work packages at the start of the project. }\end{array}$ \\
\hline P1-P2 & $\begin{array}{l}\text { Documents are produced at different stages of the project that lead to the } \\
\text { development of a paper trail. }\end{array}$ \\
\hline
\end{tabular}

\section{Step 4: Managing positive and negative resonance}

By reviewing the potential variability in the FRAM network we were better able to

identify examples of positive and negative resonance. Positive resonance happens when functions positively influence each other to make the system more effective. Here functions will have positive reverberations in other parts of the system and encourage a positive outcome. Negative resonance works against the positive reverberations in the system and brings the system towards stalling. For example, respondent S11 spoke of being accepted by her clients once they knew that she had connections to people they respected and were friends with, so they trusted her reputation by acquaintance. In the FRAM network < build reputation $>$ positively reverberates with $<$ persuade client $>$, which has a big potential influence on negotiating the project, delivering the results to the client and knock-on effects to other parts of the project. Respondents W8 and W9 found it easy to cost justify usability work and had a wealth of practical experience and examples that would help with persuading, negotiation and reputation. In contrast, respondent $\mathrm{W} 1$ found it hard to cost justify usability work, had little practical experience, and used examples from textbooks. Here aspects of reputation and 
experience had a direct impact on project work and the practitioner relationship with the client or the broader design team.

Like how a new player signed up to a sports team can influence many different aspects of the team, so to can changes to functions in the system of human factors practice. The most obvious example would be to hire a high performing human factors practitioner, who is shown as a resource or control in the network diagram. They could introduce new tools, methods and practices; manage a new range of projects and clients; and possibly nurture and mentor other practitioners within the company. Multiple positive reverberations could also be introduced by doing something like getting the client to directly observe usability testing. This has the potential to speed the delivery of the results i.e. they don't have to wait for the written report, it can improve client buy-in as they are directly observing users, it affords more opportunity to develop rapport, and it can allow for timely client feedback to make the test more effective and relevant for their needs. We include further highlights of positive and negative resonance in Table 4. [Insert Table 4 about here]

Table 4. Examples of positive and negative resonance from practitioners (W\# = usability practitioner from the website domain; $\mathrm{S} \#=$ human factors practitioner from the safety-critical domain).

\begin{tabular}{|l|l|l|l|}
\hline Theme & Positive Resonance & Negative Resonance & Link to FRAM network \\
\hline $\begin{array}{l}\text { Understanding } \\
\text { client's need. }\end{array}$ & $\begin{array}{l}\text { Respondent W8 spoke of } \\
\text { helping the client } \\
\text { understand their need, } \\
\text { because they sometimes } \\
\text { did not fully understand } \\
\text { it themselves. }\end{array}$ & $\begin{array}{l}\text { W5 satisfied his } \\
\text { contacts' need but then } \\
\text { found that his contacts' } \\
\text { managers had other } \\
\text { concerns that nullified } \\
\text { his contribution. His } \\
\text { contact had not } \\
\text { understood these deeper } \\
\text { constraints and needs in } \\
\text { advance. }\end{array}$ & $\begin{array}{l}\text { The coupling between the } \\
\text { first six functions in the } \\
\text { network area critical in the } \\
\text { set-up of the project. The } \\
\text { client and practitioner need } \\
\text { to have a clear } \\
\text { understanding of the } \\
\text { client's need to an } \\
\text { appropriate project can be } \\
\text { designed and so the client } \\
\text { will be satisfied with the } \\
\text { outcome. }\end{array}$ \\
\hline
\end{tabular}




\begin{tabular}{|c|c|c|c|}
\hline Theme & Positive Resonance & Negative Resonance & Link to FRAM network \\
\hline $\begin{array}{l}\text { Frequency of } \\
\text { communication. }\end{array}$ & $\begin{array}{l}\text { Respondent W2, who } \\
\text { was involved in design } \\
\text { work, greatly valued } \\
\text { their company's } \\
\text { procedure for frequently } \\
\text { communicating with the } \\
\text { client, to make sure both } \\
\text { parties understood each } \\
\text { other, so the project } \\
\text { could be corrected } \\
\text { should it need to be. }\end{array}$ & $\begin{array}{l}\text { Respondent W1 makes a } \\
\text { comment which contrasts } \\
\text { with the way W2 refers } \\
\text { to design, saying: "you } \\
\text { design it, you ship it out } \\
\text { to another team, either } \\
\text { they're happy with or } \\
\text { they're not, if they're not } \\
\text { happy then you argue } \\
\text { with them." This is not } \\
\text { as communicative or } \\
\text { collaborative. }\end{array}$ & $\begin{array}{l}<\text { Building rapport }>\text { is } \\
\text { coupled to }<\text { persuading the } \\
\text { client }>\text { which is } \\
\text { highlighted in negotiating } \\
\text { the work, doing the project } \\
\text { work, and communicating } \\
\text { the results to the client. } \\
\text { Good communication and } \\
\text { collaboration helps } \\
\text { facilitate how these } \\
\text { functions work together in } \\
\text { a positive way. }\end{array}$ \\
\hline $\begin{array}{l}\text { Tool support to } \\
\text { enhance } \\
\text { abilities. }\end{array}$ & $\begin{array}{l}\text { Respondent } \mathrm{S} 10 \\
\text { remarked about the } \\
\text { considerable time he } \\
\text { could save since the } \\
\text { development of a tool } \\
\text { that helped him calculate } \\
\text { workload analyses. }\end{array}$ & $\begin{array}{l}\text { Respondents W4 and S7 } \\
\text { both identified editing } \\
\text { video to be a chore, } \\
\text { which is a barrier to } \\
\text { choosing this. }\end{array}$ & $\begin{array}{l}\text { Developing a tool and } \\
\text { selecting a tool can have a } \\
\text { positive or negative impact } \\
\text { on what project work is } \\
\text { performed and what } \\
\text { analyses is done. This feeds } \\
\text { into <work packages are } \\
\text { developed>. }\end{array}$ \\
\hline $\begin{array}{l}\text { Development of } \\
\text { human factors } \\
\text { output } \\
\text { practices. }\end{array}$ & $\begin{array}{l}\text { Respondent W5, was } \\
\text { proud of the } \\
\text { development work they } \\
\text { had done on their } \\
\text { reporting procedures. } \\
\text { These developments } \\
\text { made the reports faster to } \\
\text { produce, gave the detail } \\
\text { for the people that } \\
\text { needed it, and a high } \\
\text { level section for those } \\
\text { that didn't need it and } \\
\text { aren't interested in it. } \\
\text { The development also } \\
\text { included it being 'pretty' } \\
\text { so it was more appealing } \\
\text { and engaging as a } \\
\text { product. }\end{array}$ & $\begin{array}{l}\text { Respondent W1, didn't } \\
\text { feel like they had a } \\
\text { suitable way of selecting } \\
\text { issues to communicate to } \\
\text { the client. There were } \\
\text { processes in place but } \\
\text { they had no support from } \\
\text { senior management and } \\
\text { so no one had confidence } \\
\text { in them or the motivation } \\
\text { to use them. }\end{array}$ & $\begin{array}{l}\text { This shows how <reporting } \\
\text { practices are developed }> \\
\text { has reverberations through } \\
\text { to what reporting practices } \\
\text { are selected, how the client } \\
\text { engages with the results } \\
\text { and how they understand } \\
\text { the results. } \\
\text { It also alludes to how a lack } \\
\text { of support and direction } \\
\text { from senior management } \\
\text { can negatively impact the } \\
\text { performance of the system, } \\
\text { especially where more } \\
\text { inexperienced human } \\
\text { factors practitioners feel } \\
\text { challenged. }\end{array}$ \\
\hline
\end{tabular}

\section{Respondent Validation}

Generally respondents thought the elements of the model were accurate and played a

significant part in their work. The qualitative feedback from respondents provided a

further opportunity for reflection in terms of clarifying results, incorporating different

perspectives and explaining discrepancies. A summary of all the feedback, including

frequency data on accuracy, significance and qualitative feedback from each respondent

can be found in Appendix D of Furniss (2008). 
In some cases incorporating different opinions and perspectives was a challenge, especially where they conflicted. For example E11 thought the model was missing detail and complexity - suggesting it could be expanded, whereas E14 thought it overly complex - suggesting it could be reduced. Both views are valid. The challenge is to find a good balance, which we feel had been achieved from the positive feedback from respondents.

Hollnagel (2012a) has drawn a distinction between a FRAM model and an instantiation of that model. The model is a generalizable description of the system in terms of its functions but it does not go into detail about a particular scenario. From one general model there might be different instantiations with different details and outcomes. This mechanism allows one to use abstraction to aggregate across different cases, projects and interviews. For the respondent validation it helped rationalise some of the different opinions and perspectives from our respondents. For example, S2 points out that not all clients are willing to enter into a negotiation process; some respondents indicated that developing a paper trail is not significant but others said it is very important; some said the hierarchical description of management and staff development did not apply to their circumstances whilst others said it was accurate; and respondents indicated that the frequency of client communication is project dependent. S2 also points out that a tool or method might be the stated objective of project work rather than a report. These variations can be rationalised through a general model, and then different instantiations of this depending on the practices at a local level. 


\section{Discussion}

This section reflects on the applicability of using FRAM beyond safety, exploring how sociotechnical systems stall and flourish, and the usability of FRAM and how we have adapted it for our case study.

\section{The applicability of using FRAM to model how systems flourish and stall}

The main contribution of this paper is a case study of FRAM that explores the

effectiveness of a system outside the safety domain. Whereas applications have focused on uncontrolled performance variability and safety concerns within safety domains, our application explores the method outside safety with the broad remit of effective performance. Periera (2013) also expand the scope of FRAM to issues of effectiveness; however, this mainly covers unwanted events and loss of effectiveness. By focusing on positive resonance, we can identify how well functions work together in a system: e.g., on successful outcomes, gains in effectiveness and configurations of sociotechnical system that have potential to excel. This has opened up new concerns and potentials for the method.

Other methods could be explored to model positive performance in complex systems. For example, STAMP (Leveson, 2004) foregrounds 'constraints' as the method of control in complex systems, and emphasises the role of 'dynamic feedback loops'. Reflecting on our case study we can envisage an account of human factors professionals developing a model of their project work through dynamic feedback loops, whilst exploring and setting constraints for successful project performance, so it can be successfully managed. Here the constraints should allow a space for growth and successful adaptations, and feedback should be responded to so the system flourishes. However, we have focused on FRAM rather than STAMP for at least two reasons: 1) the concept of positive resonance captures the non-linear impact of functions in our case 
study well and suits this method; and 2) FRAM seems to allow for more flexibility in modelling interactions between the functions in human factors project work rather than emphasizing feedback loops in an extended hierarchy from work and staff processes, to management to company, to regulators and government.

This case study provides evidence that FRAM can be used to explore the effectiveness of processes in complex sociotechnical systems. Emergent performance can be analysed through assessing how multiple component functions interact with each other. By focusing on how parts work well together and how to improve or excel in performance, rather than guarding against uncontrolled performance variability, FRAM is repurposed for broader quality management purposes. FRAM can be used to examine the tangled network of functions in complex systems to gain insight into what can lead them to stall or flourish.

The sub-network themes from our case study provide a preliminary focus and structure for examining other complex sociotechnical systems using FRAM. Broad systems can be described as a single function, e.g. the system of human factors practice could be $<$ provide human factors guidance $>$ and a hospital could be $<$ treat patients $>$. However, this level of description is not interesting. These functions can be broken down into more complex description that provides insight into how the system works. Through our case study we have broken down the functional system into a central process, and then sub-networks that integrate and impact this process. Table 5 provides an overview of how our sub-network themes can be related to themes at a higher level with broader applicability, and then how these themes could guide analyses of other sociotechnical systems. We have taken home haemodialysis as an illustrative example, based on earlier 
analyses (Rajkomar et al. 2014, 2015), but without yet conducting a FRAM analysis of this system.

[Insert Table 5 about here]

Table 5. How themes from our case study relate to broader themes that could guide the initial focus of FRAM analyses of other sociotechnical systems, using home haemodialysis as an example.

\begin{tabular}{|l|l|l|}
\hline $\begin{array}{l}\text { Sub-networks in } \\
\text { our case study }\end{array}$ & Broader themes & $\begin{array}{l}\text { Potential focuses for studying home } \\
\text { haemodialysis using FRAM }\end{array}$ \\
\hline $\begin{array}{l}\text { Central project } \\
\text { process }\end{array}$ & $\begin{array}{l}\text { Central activities } \\
\text { and tasks }\end{array}$ & $\begin{array}{l}\text { The variability in how patients treat } \\
\text { themselves, maintain equipment, } \\
\text { manage supplies, etc. }\end{array}$ \\
\hline $\begin{array}{l}\text { Analytic insight } \\
\text { and project } \\
\text { understanding }\end{array}$ & Individual factors & $\begin{array}{l}\text { The variability of the knowledge, } \\
\text { understanding and emotions of } \\
\text { different patients and carers. }\end{array}$ \\
\hline $\begin{array}{l}\text { Persuasion, } \\
\text { rapport and } \\
\text { reputation }\end{array}$ & $\begin{array}{l}\text { Interpersonal } \\
\text { factors }\end{array}$ & $\begin{array}{l}\text { The variability in factors affecting how } \\
\text { easily patients interrelate with their } \\
\text { broader network through visits, phone } \\
\text { calls, emails, deliveries, etc. }\end{array}$ \\
\hline $\begin{array}{l}\text { Managing staff } \\
\text { development and } \\
\text { supervision }\end{array}$ & $\begin{array}{l}\text { Team and } \\
\text { organisational } \\
\text { factors }\end{array}$ & $\begin{array}{l}\text { The variability in how friends, relatives } \\
\text { and different professional staff support } \\
\text { their treatment. }\end{array}$ \\
\hline $\begin{array}{l}\text { Tools, methods } \\
\text { and reporting } \\
\text { practices }\end{array}$ & $\begin{array}{l}\text { Resources and } \\
\text { equipment }\end{array}$ & $\begin{array}{l}\text { The variability in how different } \\
\text { equipment and machines impact the } \\
\text { process and broader system. }\end{array}$ \\
\hline $\begin{array}{l}\text { Documentation } \\
\text { and auditing }\end{array}$ & $\begin{array}{l}\text { Knowledge } \\
\text { sharing and } \\
\text { quality control }\end{array}$ & $\begin{array}{l}\text { The variability in the knowledge } \\
\text { sharing between patients (e.g. in } \\
\text { support groups and discussion } \\
\text { forums), between patients and staff, } \\
\text { and between staff. Also, the } \\
\text { effectiveness of incident reporting } \\
\text { when healthcare is in the community. }\end{array}$ \\
\hline
\end{tabular}

Step 4 in FRAM proposes ways to manage variability, and our case study identifies examples of positive and negative resonance in human factors projects, i.e. instances that could lead the project to stall or flourish. It is easier to arrive at these instances once there has been a systematic review of the functional variance and resonance using 
FRAM, i.e. Steps 1-3. Once a list of examples of potential positive and negative resonance of a particular context have been established these could be used to prime for other examples from experts. This is part of future work for our context, and could be used for other complex systems too. Different stakeholders in the sociotechnical system could have different perspectives on what is important to prevent stalling and to encourage the system to succeed.

\section{The usability of FRAM and practical modifications}

Besides the modification of applying FRAM to model positive performance we also experienced a number of issues of FRAM in its current form that encouraged smaller modifications to make it more usable. For example, we created a template (Figure 5 and Figure 6) to capture the six aspects, common performance conditions (CPCs), and supporting qualitative data for each function. This helped organise and track this detail for each of the 29 functions. We did not apply a rating for all of the 11 CPCs for all of the 29 functions as we judged it would be of little benefit compared to the cost for our case study, instead we just highlighted the important ones to consider.

Our approach to the FRAM analysis was one of creating a network that was grounded in our data. This involved inductive reasoning and creative elements, e.g. recognising repeated patterns across the interviews, brainstorming lists of functions and configurations of network diagrams to test against the data, and filtering out what was important. For example, the initial FRAM network was too dense with links, we needed to organise the hexagons and links (with some hidden through a coding scheme) so it was usable.

Attempting respondent validation was also a novel modification to try to ensure that our model contained the right elements and was accurate. This necessitated that we make the model understandable to others outside of the research team, i.e. it became a tool for 
communication and not just for analysis. We presented it via email to human factors practitioners in a report that first described the 29 functions, then the 6 sub-systems, and then the overall system. The sub-systems proved to be a useful mechanism for breaking down the model into smaller more manageable networks. Themes from the sub-systems we developed could potentially be reused for analysing other complex sociotechnical systems, like the home haemodialysis example described previously. Furthermore, a table to highlight both positive and negative forms of resonance, and how it links to the FRAM network, could also be a useful output from analysing how other complex sociotechnical systems can flourish and stall.

\section{Limitations}

The applicability of FRAM and positive resonance only became apparent after data collection and initial analyses using Grounded Theory (Furniss et al., 2011). In terms of data gathering, this meant that we gathered more general data during the conduct of our interviews, without the aim of applying FRAM. If we had known we would apply FRAM from the outset we might have asked questions to prompt interviewees to give us detail on variability they had experienced in their work and what they might recognise as critical couplings, e.g. exploring time and resource constraints could encourage discussion about the variability between when these are tight and when they are abundant. In terms of analysis, this meant that FRAM was a secondary analysis overlaid on a detailed coding scheme. Functions were recognised by abstracting and aggregating across interviews to find patterns to create a general model. This received positive feedback from human factors and usability professionals who were both internal and external to the study, which was reported in the respondent validation's results. We have focused on engaging with human factors and usability professionals; however, future research could look at the perspective of other actors in the system, e.g. 
clients and developers, who may emphasise different functions and features in the system.

\section{Conclusion}

This case study evaluates the applicability and usability of FRAM beyond its typical focus on safety and uncontrolled performance variability. We apply FRAM to examine the variability and effectiveness of human factors project work. To achieve this we have introduced the novel concept of positive resonance. This turns our attention away from unwanted events and loss of effectiveness, to gains in effectiveness and to potential configurations of sociotechnical systems that can excel. This opens up new concerns and potential for FRAM. Our use of FRAM provides evidence that it can be used to investigate the tangled network of functions that comprise complex sociotechnical systems, and identify instances of positive and negative resonance, that could lead the system to flourish or stall. It also shows how we have adapted the method to make it more usable. For example, by creating a template to track the detail of functions, creating a complex FRAM network with more manageable sub-networks, and performing respondent validation to check the model is accurate and understandable to those outside of the research team.

\section{References}

Belmonte, F., Schön, W., Heurley, L., \& Capel, R. (2011). Interdisciplinary safety analysis of complex socio-technological systems based on the functional resonance accident model: An application to railway traffic supervision. Reliability Engineering \& System Safety, 96(2), 237-249.

Berndt, E., Furniss, D., \& Blandford, A. (2014). Learning Contextual Inquiry and Distributed Cognition: a case study on technology use in anaesthesia. Cognition, Technology \& Work, 1-19. 
Blandford, A. E., Hyde, J. K., Green, T. R., \& Connell, I. (2008). Scoping analytical usability evaluation methods: a case study. Human-Computer Interaction, 23(3), 278-327.

Blandford, A., Keith, S, \& Fields, B. (2006). Claims Analysis 'in the wild': a case study on Digital Libraries. International Journal of Human-Computer Interaction, 21(2), 197-218.

Boren, T., \& Ramey, J. (2000). Thinking aloud: Reconciling theory and practice. Professional Communication, IEEE Transactions on, 43(3), 261-278

Chamberlain, K., Camic, P., \& Yardley, L. (2004). Qualitative Analysis of Experience: Grounded Theory and Case Studies. In D. Marks \& L. Yardley (Eds.), Research Methods for Clinical and Health Psychology (pp. 69-89). Sage Publications.

De Carvalho, P. V. R. (2011). The use of Functional Resonance Analysis Method (FRAM) in a mid-air collision to understand some characteristics of the air traffic management system resilience. Reliability Engineering \& System Safety, 96(11), 1482-1498.

Dijkstra, A. (2006). Resilience Engineering and Safety Management Systems in aviation. In E. Hollnagel \& E. Rigaud (Eds.), Proceedings of the Second Resilience Engineering Symposium (pp. 92-104).

Frost, B., \& Mo, J. P. (2014). System Hazard Analysis of a Complex Socio-Technical System: The Functional Resonance Analysis Method in Hazard Identification.

Furniss, D. (2008). Beyond problem identification: valuing methods in a 'system usability practice' (Doctoral dissertation, UCL (University College London)).

Furniss, D., Blandford, A. \& Curzon, P. (2007). Resilience in Usability Consultancy Practice: the case for a positive resonance model. In R. Woltjer, B. Johansson \& J. Lundberg (Eds.) Proceedings of Resilience Engineering Workshop, Vadstena, Sweden. June. Linköping Electronic Conference Proceedings, 23(5), 31-35.

Furniss, D., Blandford, A., \& Curzon, P. (2011). Confessions from a grounded theory $\mathrm{PhD}$ : experiences and lessons learnt. In Proceedings of the CHI 2011 Conference on Human Factors in Computing Systems (pp. 113-122). ACM.

Gray, W. D., \& Salzman, M. C. (1998). Damaged merchandise? A review of experiments that compare usability evaluation methods. Human-Computer Interaction, 13(3), 203-261. 
Hartson, H. R., Andre, T. S., \& Williges, R. C. (2003). Criteria for evaluating usability evaluation methods. International Journal of Human-Computer Interaction, 15(1), 145-181.

Heinrich HW, Peterson D \& Roos N (1980), Industrial Accident Prevention, $5^{\text {th }}$ Edition, Mcgraw Hill, New York

Herrera, I. A., \& Woltjer, R. (2010). Comparing a multi-linear (STEP) and systemic (FRAM) method for accident analysis. Reliability Engineering \& System Safety, 95(12), 1269-1275.

Hollnagel, E. (2004). Barriers And Accident Prevention. Ashgate Publishing, Ltd.

Hollnagel, E. (2012a). FRAM: the functional resonance analysis method: modelling complex socio-technical systems. Ashgate Publishing, Ltd.

Hollnagel, E. (2012b). The ETTO principle: efficiency-thoroughness trade-off: why things that go right sometimes go wrong. Ashgate Publishing, Ltd.

Hollnagel, E. (2014). Safety-I and Safety-II: The Past and Future of Safety Management. Ashgate Publishing, Ltd.. Epstein, 2008

Hollnagel, E. \& Hill R. (2015). FRAM Model Visualiser Instructions. version 0.3.2. www.functionalresonance.com/onewebmedia/FMV_instructions_0.3.2.pdf, (accessed 07 September 2015).

Hollnagel, E., Pruchnicki, S., Woltjer, R., \& Etcher, S. (2008). Analysis of Comair flight 5191 with the functional resonance accident model. In 8th International Symposium of the Australian Aviation Psychology Association (pp. 8-pages).

Hornbæk, K. (2010). Dogmas in the assessment of usability evaluation methods. Behaviour \& Information Technology, 29(1), 97-111.

John, B. E., \& Packer, H. (1995, May). Learning and using the cognitive walkthrough method: a case study approach. In Proceedings of the SIGCHI conference on Human factors in computing systems (pp. 429-436). ACM Press/AddisonWesley Publishing Co.

Leveson, N. (2004). A new accident model for engineering safer systems. Safety science, 42(4), 237-270.

Lundblad, K., Speziali, J., Woltjer, R., \& Lundberg, J. (2008). FRAM as a risk assessment method for nuclear fuel transportation. International Confererence Working on Safety, 2008. 
Newman, W. (1994). A preliminary analysis of the products of HCI research, using pro forma abstracts. In Proceedings of the CHI conference on Human factors in computing systems (pp. 278-284). ACM.

Nielsen, J., and Molich, R. (1990). Heuristic evaluation of user interfaces, Proc. ACM CHI'90 Conf. (Seattle, WA, 1-5 April), 249-256

Nouvel, D., Travadel, S., \& Hollnagel, E. (2007). Introduction of the Concept of Functional Resonance in the Analysis of a Near-Accident in Aviation. In 33rd ESReDA Seminar: Future challenges of accident investigation (pp. 9-pages).

Nørgaard, M., \& Hornbæk, K. (2006). What do usability evaluators do in practice?: an explorative study of think-aloud testing. In Proceedings of the 6th ACM conference on Designing Interactive systems (pp. 209-218).

Olmsted-Hawala, E. L., Murphy, E. D., Hawala, S., \& Ashenfelter, K. T. (2010). Thinkaloud protocols: a comparison of three think-aloud protocols for use in testing data-dissemination web sites for usability. In Proceedings of the sigchi conference on human factors in computing systems (pp. 2381-2390). ACM.

Pereira, A. G. (2013). Introduction to the Use of FRAM on the effectiveness assessment of a radiopharmaceutical Dispatches process. In Proceedings of the International Nuclear Atlantic Conference. Brazilian Association of Nuclear Energy, Rio de Janeiro.

Rajkomar, A., Farrington, K., Mayer, A., Walker, D., \& Blandford, A. (2014). Patients' and carers' experiences of interacting with home haemodialysis technology: implications for quality and safety. BMC nephrology, 15(1), 195.

Rajkomar, A., Mayer, A., \& Blandford, A. (2015). Understanding safety-critical interactions with a home medical device through Distributed Cognition. Journal of biomedical informatics, 56, 179-194.

Reason, J. (1997). Managing the risks of organizational accidents. Ashgate Publishing Ltd.

Spencer, R. (2000). The streamlined cognitive walkthrough method, working around social constraints encountered in a software development company. In Proceedings of the SIGCHI conference on Human Factors in Computing Systems (pp. 353-359). ACM.

Weick, K. E., \& Sutcliffe, K. M. (2007). Managing the Unexpected: Resilient Performance in and Age of Uncertainty, Second Edition. San Francisco, CA: Jossey-Bass. 
Wharton, C., Rieman, J., Lewis, C., \& Polson, P. (1994). The cognitive walkthrough method: A practitioner's guide. In Usability inspection methods (pp. 105-140). John Wiley \& Sons, Inc.

Wixon, D. (2003). Evaluating usability methods: why the current literature fails the practitioner. Interactions, 10(4), 28-34.

Woltjer, R., \& Hollnagel, E. (2008). Functional modeling for risk assessment of automation in a changing air traffic management environment. In Proceedings of the 4th International Conference Working on Safety.

Woolrych, A., Hornbæk, K., Frøkjær, E., \& Cockton, G. (2011). Ingredients and meals rather than recipes: A proposal for research that does not treat usability evaluation methods as indivisible wholes. International Journal of HumanComputer Interaction, 27(10), 940-970. 
Table 1. The 29 functions of human factors project work using FRAM.

Table 2. First three functions in FRAM model and their summary description.

Table 3. Codes for functional coupling in human factors practice.

Table 4. Examples of positive and negative resonance from practitioners.

Table 5. How themes from our case study relate to broader themes that could guide the initial focus of FRAM analyses of other sociotechnical systems, using home haemodialysis as an example. 
Figure 1. Performance variability of functions (from high to low) against time. Each faint wavey line represents the output of a function, whereas the bold line represents the summative effect of these outputs (adapted from Dijkstra, 2006, p. 97).

Figure 2. Performance variability of functions (from high to low) against time. Each faint wavey line represents the output of a function, whereas the bold line represents the summative effect of these outputs. Functions can exceed normal margins of quality and control.

Figure 3. A function and its six aspects.

Figure 4. An example of how functions can be coupled, represented in FRAM's visual notation, using the FRAM Model Visualiser tool. The tool automatically greys out functions that only have one connection as they are likely to be a background function.

Figure 5. Sections of the template used for Steps 1 and 2 of the FRAM analysis.

Figure 6. Full description of Function 2 - Human Factors practitioner develops understanding of client need.

Figure 7. FRAM Model Visualiser screenshot.

Figure 8. Positive resonance model of human factors practice. 